\title{
DEFINING GEOGRAPHIC MARKETS FOR HOSPITAL CARE
}

\author{
Michael A. Morrisey, * \\ Frank A. Sloan, $†$ \\ AND JOSEPH VALVONA**
}

I

\section{INTRODUCTION}

There is a substantial body of economic literature discussing various approaches to delimiting geographic markets. ${ }^{1}$ These approaches, however, seldom have been applied to analyses of hospital markets. With the growth of multihospital systems ${ }^{2}$ and the increased interest of the Federal Trade Commission and the United States Department of Justice in examining competition in the health care sector, ${ }^{3}$ the definition of hospital markets has become increasingly important.

Until recently, efforts to examine hospital competition and efforts to allow for competing firms in analyses of hospital behavior have used geopolitical boundaries to describe hospital markets. ${ }^{4}$ These market definitions are handy, but probably economically meaningless; nevertheless, they have come to serve as the basis for new hospital payment mechanisms and have been

Copyright (C) 1989 by Law and Contemporary Problems

* Professor, Department of Health Care Organization and Policy, University of Alabama at Birmingham.

This study was funded in part by grant H505176 from the National Center for Health Services Research and Health Care Technology Assessment. We thank Stephen Murray and Athena Wang for excellent research assistance and Jonathan Baker, James Blumstein, and Gregory Vistnes for helpful comments.

$\dagger$ Centennial Professor of Economics and Director, Health Policy Center, Institute for Public Policy Studies, Vanderbilt University.

** Health Planner, Vanderbilt Medical Center.

1. See, e.g., Elzinga \& Hogarty, The Problem of Geographic Market Delineation in Antimerger Suits, 18 Antitrust Bull. 45 (1973) [hereinafter Elzinga \& Hogarty, Geographic Market Delineation]; Horowitz, Market Definition in Antitrust Analysis: A Regression-Based Approach, 48 S. Econ. J. I (1981); Scheffman \& Spiller, Geographic Market Definition under the U.S. Department of Justice Merger Guidelines, 30 J. L. \& Econ. 123 (1987); Shrieves, Geographic Market Areas and Market Structure in the Bituminous Coal Industry, 23 Antrtrust Bull. 589 (1978); Spiller \& Huang, On the Extent of the Market: Wholesale Gasoline in the Northeastern United States, 35 J. Indus. Econ. 131 (1986); Stigler \& Sherwin, The Extent of the Market, 28 J. L. \& Econ. 555 (1985); Werden, Market Delineation and the Justice Department's Merger Guidelines, 1983 DUKE L.J. 514.

2. By $1985,38 \%$ of hospital beds and $35 \%$ of U.S. community hospitals were owned, leased, sponsored, or managed by multihospital systems. Alexander, Lewis \& Morrisey, Acquisition Strategies of Multihospital Systems, Health Afrs., Fall 1985 at 49, 50. Between 1976 and 1985, the number of hospitals owned by systems grew at an average annual rate of $5.3 \%$. Id. at 55 .

3. See American Medical Int'l, 104 F.T.C. 1 (1984); Hospital Corp. of Am., 106 F.T.C. 361 (1985); Competition in the Health Care Sector: Past, Present, and Future (W. Greenberg ed. 1978) (proceedings of an FTC sponsored conference on the issues).

4. See infra text accompanying note 11 . 
used to segregate some hospitals for special payment considerations. ${ }^{5}$ The use of geopolitical boundaries has also led to the conclusion that the hospital industry is highly concentrated. Salkever noted, for example, that, in 1974, eighty-four Standard Metropolitan Statistical Areas ("SMSA's") had fewer than four hospitals. ${ }^{6}$ Joskow assumed that rural hospitals in single-hospital counties have no competitors. ${ }^{7}$ Yet there has been almost no attempt to use any of the industrial organization literature's definitions of markets to identify the actual size of a hospital's geographic market or to gauge the extent of concentration in that market.

Patient origin data are used in this study to define empirically the size of hospital geographic markets. Special attention is devoted to rural areas where hospitals are often assumed to be monopolists. The study examines the consequences of alternative treatments of the definition of a hospital's products. Finally, the implications of these findings are discussed as they relate to antitrust policy.

\section{II}

\section{BACKGROUND}

\section{A. Definition of a Market}

There are two aspects to defining a market for purposes of antitrust analysis. One must define first the market for the product of interest and, second, the geographic market in which trade in the product occurs. For both product and geographic market definitions, two types of substitutability are relevant: demand substitutability and supply substitutability. ${ }^{8}$ Demand substitutability depends upon the extent to which consumers of the good or service are able to switch to substitutes for that good or service in response to a price increase. In contrast, supply substitutability depends upon the extent to which existing providers could expand output, and/or firms not currently producing the good or service could enter the market for that good or service.

In specific applications, the product market is defined first. Then, given a definition of product, the geographic area over which commerce in the

5. The Medicare prospective payment system makes distinctions in payment for urban and rural hospitals and for hospitals that are "sole community providers." Sole providers are either located more than 50 miles from other hospitals; or are located 25 to 30 miles from other hospitals and meet other criteria; or are located 15 to 25 miles from other hospitals and have a unique topology that restricts travel. 48 Fed. Reg., 39,780 (1983).

6. Salkever, Competition Among Hospitals, in Competition in the Health Care Sector, supra note 3, at 149, 151. L. Russell, Technology in Hospitals: Medical Advances and Their Diffusion 26 (1979), indicates that only 36 of the 256 SMSA's had four-firm concentration ratios below $50 \%$ in 1975 .

7. Joskow, The Effects of Competition and Regulation on Hospital Bed Supply and the Reservation Quality of the Hospital, 11 BELL J. ECON. 421, 436 (1980) (assumes hospitals in rural areas to have a Herfindahl-Hirshman Index value of 10,000). See also Luft \& Maerki, Competitive Potential of Hospitals and Their Neighbors, 3 Contemp. Pol'y Issues 89, 100 (1984/85) ("Almost by definition, hospitals without any neighbors within a 15 -mile radius (707 square miles) have some monopoly powers. Hospitals with a small number of neighbors may act as local monopolies or as members of a cartel.").

8. See, e.g., R. Blair \& D. Kaserman, Antitrust Economics 106-10 (1985); Landes \& Posner, Market Power in Antitrust Cases, 94 Harv. L. Rev. 937, 944-52 (1981). 
product takes place is examined. Geographic markets for products are limited to a greater or lesser extent by (1) the cost of transporting the product and (2) legal barriers, such as those imposed by entry regulation, that may prohibit trade among jurisdictions. Transportation costs of shipment between two areas may create a differential in prices in the two areas. When the cost of transportation is high relative to cost of production, geographic markets tend to be small; the converse holds true when relative transportation cost is low.

The Department of Justice has developed Merger Guidelines for the purpose of evaluating the potentially anticompetitive effects of mergers. ${ }^{9}$ The DOJ Guidelines adopted the following basic definition of a market:

Formally, a market is defined as a product or group of products and a geographic area in which it is sold such that a hypothetical, profit-maximizing firm, not subject to price regulation, that was the only present and future seller of those products in that area would impose a "small but significant and nontransitory" increase in price above prevailing and future levels. ${ }^{10}$

The DOJ Guidelines define a market for antitrust purposes as the smallest geographic area and group of producers that, if combined into a cartel, could profitably exercise monopoly power-that is, set a price above the level that would prevail under competition. The DOJ Guidelines concept of a market is that of an antitrust market, that is, the ability of a set of producers to raise prices if they could completely coordinate their price-output decisions. This market may be larger or smaller than the "economic market," which is delineated in terms of the transport cost of shipping the product." For two areas to be in the same economic market, the difference in product prices must be less than the transport cost between the locations. For antitrust markets, the focus is on product price changes. The ability of the cartelized group of producers to raise prices depends on the price elasticity of demand faced by the cartel. Market power varies inversely with this elasticity. A low price elasticity of demand confers market power on the hypothetical cartel. If a member of the cartel were to be erroneously excluded from the group, the cartel's price elasticity of demand would increase since the excluded member would be able to attract customers away from the cartel by not following the cartel's price increase. If the cartel as a whole does not have market power, neither would two merging firms that form a subset of the cartel.

The hypothetical cartel is a theoretical concept used to define an antitrust market. In practice, it is likely that the fewer the number of firms in the relevant market, the greater the likelihood that the firms can successfully collude. ${ }^{12}$

9. U.S. Dep't of Justice Merger Guidelines, June 14, 1984 [hereinafter 1984 Merger Guidelines].

10. Id. at 3.

11. See Scheffman \& Spiller, supra note 1, at 127; Spiller \& Huang, supra note 1, at 132.

12. See Stigler, $A$ Theory of Oligopoly, 72 J. Pol. Econ. 44, 44, 51, 52-53 (1964). In addition to the number of rival firms, Stigler contends that factors such as the number of buyers, the proportion of new buyers, and the relative sizes of firms all influence the price of goods. Id. at 56 . 
The DOJ Guidelines indicate how the U.S. Justice Department will define product and geographic markets. Relevant evidence for product market definition includes information on buyers' perceptions that goods or services are substitutes, product price movements, similarities or differences in product usage or design, and sellers' perceptions that the goods or services are substitutes. ${ }^{13}$ For purposes of determining the geographic market, the Department will consider data on product shipment patterns, indications that buyers would change sellers in response to a change in relative price, product price movements, transportation costs, costs of local distribution, and excess capacity of firms outside the location of the merging firms. ${ }^{14}$

\section{B. Empirical Approaches for Defining Markets}

The approaches to geographic market area definition described above also appear in the academic literature. Several studies have proposed price tests. ${ }^{15}$ Two towns are in the same economic market if prices for the product in the two towns move together or differ by an amount up to marginal transportation cost. ${ }^{16}$ To be useful, this approach must statistically control for other relevant factors, such as changes in common factor prices. For example, the liquor store price difference between New York and Los Angeles may be less than marginal transportation cost and prices may move together not because of demand or supply-side substitutability at the retail level but because the wholesale price of liquor is an important input.

The shipments approach was described by Elzinga and Hogarty. ${ }^{17}$ In the shipments approach, one identifies that geographic area in which very little of the product is shipped in from the outside and little of that produced within the area is exported outside of it. 18 To the extent that legal restrictions and transportation costs limit the size of a product's geographic area, such factors should be reflected in shipment patterns. ${ }^{19}$ Products will not be shipped to areas where commerce is inhibited by an entry barrier, nor for a long distance when transportation cost is high relative to the cost of production. The Elzinga-Hogarty test specifies two criteria based on shipments data. For an area to be a geographic market, there must be few shipments into the area ("little in from outside," or "LIFO") and few shipments from the area to

13. 1984 Merger Guidelines, supra note 9 , at 5 .

14. Such firms with excess capacity may be willing to sell at a low price and hence undercut the cartel's price. Id. at 12-14.

15. Horowitz, supra note 1; Stigler \& Sherwin, supra note 1. See 2 P. Areeda \& D. Turner, ANTITRust LAW 1 ๆी 521-23 (1978).

16. Horowitz, supra note 1, at 7-8; Stigler \& Sherwin, supm note 1, at 557.

17. Elzinga, Defining Geographic Market Boundaries, 26 ANTTrkust But.. 739 (1981) [hereinafter Elzinga, Defining Boundaries]; Elzinga \& Hogarty, Geographic Market Delineration, supra note 1; Elzinga \&

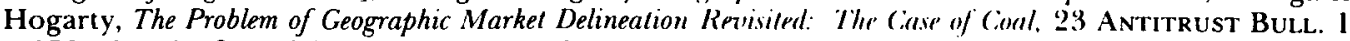
(1978) [hereinafter Elzinga \& Hogarty, The Case of Comll.

18. Elzinga \& Hogarty, Geographic Market Delineration, sumru unte 1, at 73-75; klinga \& Hogarty, The Case of Coal, supra note 17, at 2.

19. Elzinga, Defining Boundaries, supra note 17, at 7.42. 
other areas ("little out from inside," or "LOFI"). ${ }^{20}$ If an area imported a considerable amount of the product from elsewhere, producers located in the area could not raise price without losing market share to the producer of the imports. Thus, the relevant market must include the geographic area from which the imports come. If firms within the area sell much output to customers outside the area, they stand to lose their export business if they raise price and are unable to price-discriminate on the basis of distance from the plant. Thus, the relevant market must include the area to which the exports are sent.

Using the Elzinga-Hogarty approach, one looks for the smallest geographic area for which import and export flows are minimal. The authors proposed arbitrary percentage cutoffs of 75 percent and alternatively 90 percent. ${ }^{21}$ With the 75 percent standard, 75 percent of shipments by firms within the proposed market area is to customers located within the area (LOFI) and 75 percent of the output purchased by customers in the area comes from local producers (LIFO).

The residual demand approach proposed by Scheffman and Spiller ${ }^{22}$ provides a closer link to the market and market power concepts embodied in the DOJ Guidelines than either of the two other methods. It seeks to define antitrust rather than economic markets. As already noted, the potential market power possessed by a group of sellers is inversely related to the price elasticity of the demand curve they face. ${ }^{23}$ More precisely, the residual demand facing the hypothetical cartel at each price is the difference between the total or aggregate demand for the product and quantity supplied by noncartel members. ${ }^{24}$ The residual demand elasticity, and hence the market power of the cartel, varies directly with the cartel's market share and inversely with the aggregate demand curve's price elasticity and the output elasticity of the noncartel producers. ${ }^{25}$

None of the three methods is foolproof, suggesting that a combination of the methods, as suggested in the DOJ Guidelines, should be employed in specific applications. Both the price and residual demand approach require data on the price of the product. Realistically, there are often many prices for the product under scrutiny, and there is a question of which one to choose. Price data are more likely to be subject to measurement errors than are data on sales. ${ }^{26}$ Also, some future price and price-output responses that may result from a merger may not be observable from historical data.

20. Elzinga \& Hogarty, Geographic Market Delineation, supra note 1, at 73-75; Elzinga \& Hogarty, The Case of Coal, supra note 17, at 2.

21. Elzinga \& Hogarty, Geographic Market Delineation, supra note 1, at 74-75; Elzinga \& Hogarty, The Case of Coal, supra note 17, at 2.

22. Scheffman \& Spiller, supra note 1.

23. See supra p. 167.

24. See Scheffman \& Spiller, supra note 1 , at 124 n.8.

25. Landes \& Posner, supra note 8 , at 939.

26. Scheffman \& Spiller, supra note 1, at 138. 
The shipment approach also has shortcomings. For example, patterns of imports and exports, and hence the market areas, depend on product prices. If firms in a town raise prices, they may first lose customers at the distant fringe of the area they previously served. The computed market area would shrink as prices increased for this reason. Yet, the market area would expand in the sense that firms at more distant locations could successfully compete for business in the town. ${ }^{27}$

\section{Application to Hospitals}

As a first step, we define the product as acute care inpatient services. The American Hospital Association ("AHA") has defined a short-term general hospital as one with a mean length of stay of less than thirty days. ${ }^{28}$ We apply the same definition to acute care generally. Although demand for particular types of care, such as appendectomies, hernia repairs, and treatment of heart attacks, are not viewed from the buyer's perspective as substitutes, the supply of various procedures could be easily expanded in response to a price increase. General surgeons could easily switch hospital operating room time from hernia repairs to appendectomies. ${ }^{29}$ An exception to this generalization would be when a certificate of need is necessary before the hospital can provide the service, as in the cases of open heart surgery and CAT scanning.

Because of the pervasiveness of insurance coverage for hospital care, patients pay only a small part of their hospital bills. ${ }^{30}$ However, they and their relatives bear the full cost of transportation to and from the hospital. ${ }^{31}$

27. See Werden, The Use and Misuse of Shipments Data in Defining Geographic Markets, 26 ANTITRust Bull. 719, 724-27 (1981). But cf. Elzinga, Defining Boundaries, supra note 17, at 742.46 (reply to Werden).

28. American Hosp. Ass'n, Hospital Statistics xi (1986).

29. Wilder and Jacobs defined the product as individual hospital services. Wilder \& Jacobs, Antitrust Considerations for Hospital Mergers: Market Definition and Market Concentration, in 7 ADVANCES in Health Economics and Health Services Research 250 (R. Scheffler \& L. Rossiter eds. 1987). Frech criticized their approach using an argument similar to ours. Frech, Comments on Antitrust lssues, in 7 Advances in Health Economics and Health Services Research 265-66 (R. Scheffler \& L. Rossiter eds. 1987). In a recent article, Klingensmith seemed to argue for a service-based definition of hospital output on grounds that hospitals are now specializing more than previously. Klingensmith, Applying Antitrust Concepts to the Acute Care Hospital Industry: Defining the Relevant Market for Hospital Services, 13 J. Health POL. POL'y \& L. 153, 162-64 (1988). Klingensmith provides no empirical support for his position, however. Our approach to product market defintion was also advocated by Lynk. See Lynk, Antitrust Analysis and Hospital Certificate-of-Need Policy, 32 AnTitrust Bull. $61,67-68,74-75$ (1987). Two antitrust actions brought by the Federal Trade Commission in the hospital industry have also used this definition. See American Medical Int'l, 104 F.T.C. 1, 3, 17-22, 115-119, 190-94 (1984); Hospital Corp. of Am., 106 F.T.C. 361, 362, 383-85, 464-66 (1985).

For additional views on hospital product market definition, see generally Baker, The Antitrust Analysis of Hospital Mergers and the Transformation of the Hospital Industry, LAW \& ConTEMP. ProBs., Spring 1988, at 93; T. McCarthy, Emerging Competitive Issues in Health Care Markets (paper presented at the National Economic Research Associates, Inc., Eighth Annual Antitrust \& Trade Regulation Seminar, Santa Fe, N.M., July 9-11, 1987) (supporting a definition of the product as individual hospital services).

30. See Waldo, Levit \& Lazenby, National Health Expenditures, 1985, 8 Health Care Financing REV. 1, 8, 15 (1986).

31. For a discussion of the role of travel costs in the use of health services, see McGuirk \& Porell, Spatial Patterns of Hospital Utilization: The Impact of Distance and Time, 21 Inquiry 84, 84-85, 93-94 (1984). 
Moreover, their physicians face high opportunity costs in traveling to distant hospitals, ${ }^{32}$ but they, like patients, have had little reason to care about charges at the hospitals where they admit patients. Since a high proportion of the outof-pocket cost at all but the nearest facilities would be for transportation, especially in emergency and quasi-emergency situations, the conventional wisdom among experts in the health care field is that geographic markets for hospital care are highly localized. Although the hospital reimbursement system is changing, hospital charges until now have been the crucial price for purposes of defining markets for hospital care.

As a practical matter, price data are not available. Cost data, while an appropriate measure of the price for some buyers, ${ }^{33}$ are inappropriate for others. ${ }^{34}$ Existing research suggests that competition takes non-price rather than price dimensions. ${ }^{35}$ However, "shipments data" in the form of patient origin information are available for some areas and for some classes of patients. For this reason, we use this method for gauging the approximate size of geographic market areas for hospital care. To delineate the relevant antitrust market for a specific antitrust investigation, it would be necessary to combine shipment-based evidence with other types of information.

The Elzinga-Hogarty approach as applied to hospitals consists of identifying a hospital and then identifying the geographic area from which the hospital receives virtually all of its admissions. "Virtually all" has been alternatively defined as 75 and 90 percent. ${ }^{36}$ The LOFI standard addresses the demand side question by defining the firm's market in terms of few exports. Once this definition is satisfied, one asks whether patients in this geographic market receive 75 (or 90) percent of their hospital care from hospitals within this area. This LIFO rule addresses the availability of substitutes on the supply side. The relevant market is defined by the simultaneous satisfaction of both rules. Use of the 90 percent rule will always result in a larger market than use of the 75 percent rule. Choosing which percent rule to apply depends on the comparative risks of under- or overstating the size of the market.

Once the market area is defined, a Herfindahl-Hirshman Index ("HHI") is generally used to measure the extent of concentration. ${ }^{37}$ While potential collusion underlies the definition of a market area, actual collusion is thought to be facilitated when there are few large sellers in the market. The HHI is defined as the sum of the squared market shares of the firms in the relevant

32. See Robinson \& Luft, The Impact of Hospital Market Structure on Patient Volume, Average Length of Stay, and the Cost of Care, $4 \mathrm{~J}$. Health ECon., 333, 337 (1985).

33. See Danzon, Hospital 'Profits': The Effects of Reimbursement Policies, $1 \mathrm{~J}$. HEalth Econ. 29, 30, 50 (1982).

34. Sloan \& Becker, Cross-Subsidies and Paymenl for Hospilal Care, 8 J. Health Pol. Pol'y \& L. 660, 675-76 (1984) (finding that "charge" payers paid 15\% more than "cost" payers and that the differences were not attributable to differences in the costs of services delivered).

35. See infra pp. 172-74.

36. Elzinga \& Hogarty, The Case of Coal, supra note 17, at 2.

37. The calculation is performed on sales or capacity. See Blair \& Kaserman, supra note 8 , at 236-37 and references therein. 
market. The highest possible value is 10,000 , when the market is served by a monopolist. As the market becomes increasingly atomistic, the HHI approaches zero. The DOJ Guidelines state that markets with an index value in excess of 1,800 should be considered highly concentrated. In this range, mergers resulting in an increase of fifty points or more will be carefully reviewed for antitrust problems. ${ }^{38}$

\section{Prior Research on Hospitals}

Until the mid 1980's, there were few attempts to measure empirically the size of hospital markets, the extent of concentration, or the effects of concentration on hospital behavior. The hospital industry, at least under the historical conditions of nearly complete retrospective insurance, has been thought to be different from other industries because increased competitiveness in a market led to higher prices and costs and more non-price competition in that market. To the extent that such perverse relationships exist, efforts at antitrust enforcement would be counterproductive.

Most of the studies on the influence of hospital competition have not paid attention to defining the geographic market for hospital care. Rather, they have simply assumed that the market coincides with a geographic entity, such as an SMSA or a county. Whether or not this type of assumption involves a serious misspecification can only be determined from the type of data we shall present below in Part IV.

Salkever's review of the earlier literature focused upon barriers to entry and his "impression" that hospitals competed on non-price dimensions. ${ }^{39} \mathrm{He}$ did suggest, however, that hospital markets were rather concentrated. In 1974, the average SMSA had eight hospitals; eighty-four of the 288 SMSA's at that time had fewer than four hospitals. ${ }^{40}$

Rather than compete on price, it has been argued that hospitals compete on a non-price basis. One manifestation of this was in the acquisition of sophisticated technologies. Several studies, discussed below, hypothesized that hospitals located in markets with many hospital competitors had a greater incentive to engage in a "medical arms race" than their monopolistic counterparts. Most of the findings support the view that non-price competition is greater in competitive (less concentrated) hospital markets.

Louise Russell examined the effects of hospital concentration on the diffusion of intensive care units and six other technologies. ${ }^{41}$ Using 1975 data and the SMSA as the market definition, she found almost no statistically significant relationship between concentration and technological diffusion in hospitals. ${ }^{42}$ Like Russell, Paul Joskow specified the SMSA as the geographic market for hospital care in urban areas and the state as the geographic market

38. 1984 Merger Guidelines, supra note 9.

39. Salkever, supra note 6 , at $150,153$.

40. Id. at 151 .

41. Russell, supra note 6, at 158.

42. Id. at 161 . 
in rural areas. 43 Using 1976 data, he found that "reservation quality"available empty beds to meet random fluctuations in local demand for hospital care-decreased with the concentration of hospitals within a geographic market. ${ }^{44}$ This was interpreted as evidence of greater non-price competition in less concentrated markets. ${ }^{45}$

Held and Pauly reached similar conclusions of increased non-price competition in less concentrated hospital markets. ${ }^{46}$ They examined end stage renal disease ("ESRD") using 1978 data and the SMSA and county definitions of urban and rural markets, respectively. ${ }^{47}$ Their measure of hospital profitability of ESRD services increased with the $\mathrm{HHI}^{48}$ while the level of amenities decreased. ${ }^{49}$ For nuclear medicine services in hospitals, Wilson and Jadlow found that divergence from technical efficiency increased with "competitive intensity." 50 It is not clear, however, what geographic area they used in their construction of a competitive intensity factor. ${ }^{51}$

Studies by Frech and Woolley and by Noether examined charges and costs reported by hospitals. ${ }^{52}$ Both assumed that the geographic market coincides with the SMSA. ${ }^{53}$ Frech and Woolley, using 1970 data, found that increased concentration was associated with lower cost per unit of output. The results of average room and intensive care unit charges were less clear. ${ }^{54}$ Noether used 1977 and 1978 data and reached a similar conclusion regarding concentration and cost. She too obtained ambiguous results regarding charges for specific services. ${ }^{55}$

Dean Farley defined the hospital as providing generalized inpatient hospital services and used the county as the relevant geographic market. Markets with a single hospital were called "monopolistic;" those with at least five or six similarly sized facilities were "competitive."56 His tabular comparisons of 1970-1977 data showed higher costs and revenues per unit of output in competitive markets, but no statistically significant differences in

43. Joskow, supra note 7 , at 436-37.

44. Id. at $439-40$.

45. See id. at 440 .

46. Held \& Pauly, Competition and Efficiency in the End Stage Renal Disease Program, 2 J. HeAlth ECON. 95 (1983).

47. Id. at 116 .

48. Id. at 104-05.

49. Id. at 106-07.

50. Wilson \& Jadlow, Competition, Profit Incentives, and Technical Efficiency in the Provision of Nuclear Medicine Services, 13 Bell J. ECon. 472, 481 (1982).

51. Id. Wilson and Jadlow measured competitive intensity by multiplying hospital density by referral radius by population density.

52. H. Frech \& J. Woolley, Competition Among Hospitals: An Empirical Analysis (paper presented at the Allied Social Science Associations Convention, New Orleans, La., Dec. 1986); M. Noether, Competition Among Hospital.s (1987) (staff report, Bureau of Economics, Federal Trade Commission).

53. H. Frech \& J. Woolley, supra note 52, at 15; M. Noether, supra note 52, at 41.

54. H. Frech \& J. Woolley, supra note 52 , at 49.

55. M. Noether, supra note 52 , at 55-75.

56. D. Farley, Competition Among Hospitals: Market Structure and Its Relation to Utilization, Costs and Financial Position, research note 7 (Hospital Studies Program, National Center for Health Services Research, Aug. 1985). 
various measures of accounting profits. Further, the average length of stay and the number of operations per admission were higher in competitive markets.

With the exception of Luft and his colleagues, discussed below, ${ }^{57}$ only one study has actually defined a market for hospital care and examined the extent of concentration within it. Wilder and Jacobs examined one rural county and a two-county SMSA in South Carolina. ${ }^{58}$ In each case they obtained an HHI of 2,600.59 They maintained that individual hospital service was the appropriate definition of the product. ${ }^{60}$ They found HHI measures of concentration for individual services in a range from 1,300 to 7,000 in the rural county and 2,300 to 4,600 in the four-hospital urban area. ${ }^{61}$ Wilder and Jacobs were the only analysts to explicitly compare their market to the conditions for market definition found in the economics literature. Using the Elzinga-Hogarty LIFO and LOFI rules, they found that, for aggregate discharges, the rural county imported 23.5 percent of its patients and exported 26.6 percent. ${ }^{62}$ The SMSA imported 20.4 percent of treated patients while only 2.8 percent of patients received care outside the SMSA. ${ }^{63}$ They concluded that the rural market is larger than the county and that the urban market may also be larger than the SMSA. ${ }^{64}$ However, consideration of the urban market depended upon the specific procedure in question. ${ }^{65}$

Luft and his colleagues have made the most extensive examination of the geographic market for hospital care and the effects of concentration to date. However, the size of the hospital market, as constructed by Luft and Maerki, depends upon the willingness of a physician, not a patient, to travel substantial distances to treat patients in hospitals. ${ }^{66}$ They considered fifteen miles to be the maximum a physician would be willing to travel, but also considered the implications of a five-mile limit, and hospital "clusters" based upon successive additions of hospitals. ${ }^{67}$ They found that 23.1 percent of U.S. hospitals in 1972 had no competitors within fifteen miles, 17.6 percent had only one competitor, and an additional 21.0 percent of hospitals had only two competitors. ${ }^{68}$ Clusters ranged in size from five to 205 hospitals. ${ }^{69}$ They

57. See infra text accompanying note 66 .

58. Wilder \& Jacobs, supra note 29 , at 257.

59. Id. at 258 .

60. Id. at 250 .

61. Id. at 258 .

62. Id. at 260 .

63. Id.

64. Id. at 259 .

65. Id.

66. Luft \& Maerki, supra note 7 , at 91 .

67. Luft and Maerki defined a cluster to be at least five hospitals within five miles. Hospital clusters were developed by arbitrarily choosing a hospital and adding to it if at least four neighboring hospitals located within five (or 15) miles. Then, hospitals located within five (or 15) miles of the newly added hospitals continued to be added if they had at least four neighbors within the prescribed area, until there were no remaining hospitals with at least four neighbors to be added to the cluster. Id. at 98 .

68. Id. at 94 .

69. Id. at 98 . 
contended that, "[h]ospitals with a small number of neighbors [within a fifteen-mile radius] may act as local monopolies or as members of a cartel."7o

Using the fifteen-mile market definition, Robinson and Luft documented longer hospital lengths of stay, higher costs per admission and per day, and greater increases in costs in less concentrated markets. ${ }^{71}$ This is, of course, consistent with the aforementioned evidence of non-price competition in less concentrated markets. Examining specialized clinical services, however, Luft and his colleagues found no consistent pattern of offering a particular service as the number of competitors in the market increased. ${ }^{72}$

Finally, Garnick and her colleagues considered the implications for market concentration of alternative definitions of the hospital market. ${ }^{73}$ Using California data, they compared the fifteen-mile radius measure of competing hospitals with patient origin data. ${ }^{74}$ They used patient origin data to identify those zip code areas from which a hospital drew 60 percent of its admissions. ${ }^{75}$ A competitor to a hospital was said to exist if it admitted at least 5 percent of all patients in any of the hospital's zip code areas. ${ }^{76}$ Using these definitions, they determined that 27 percent of California hospitals were in markets with $\mathrm{HHI}$ values of 1,000 or less by either market definition. ${ }^{77}$ Another 37 percent were identified as having $\mathrm{HHI}$ values in excess of 1,000 by either market definition. ${ }^{78}$ Of those inconsistently classified, the Garnick patient origin approach almost always yielded a higher concentration measure than did the fifteen-mile algorithm. ${ }^{79}$

The definition of the economically appropriate market area must relate to the responsiveness of consumers and other providers to the changed behavior of a given hospital or group of hospitals. If hospitals compete on a non-price basis, the competing hospitals within the market area will react to an increase in service or amenity level at hospital A. This may have little to do with Luft and Maerki's view of the distance physicians are willing to travel. ${ }^{80}$ If patients, at the margin, make decisions independently of physician advice on which hospitals to patronize, and/or the patient's usual physician is willing to refer the patient to another physician for hospital treatment, ${ }^{81}$ then actual hospital

70. Id. at 100 .

71. Robinson \& Luft, Competition and the Cost of Hospital Care, 1972-1982, 257 J. A.M.A. 3241 (1987); Robinson \& Luft, supra note 32, at 337, 342, 350, 353.

72. Luft, Robinson, Garnick, Maerki \& McPhee, The Role of Specialized Clinical Services in Competition Among Hospitals, 23 InQUIRY 83 (1986).

73. Garnick, Luft, Robinson \& Tetreault, Appropriate Measures of Hospital Market Areas, 22 HEALTH Services Res. 69 (1987).

74. Id. at 75-76.

75. Id. at 76 .

76. Id.

77. Id. at 82 (calculated from Table 3).

78. $I d$.

79. $I d$. at 82 .

80. See Luft \& Maerki, supra note 7.

81. This would occur when an internist or general/family physician refers a patient to a hospital for a sophisticated surgical or diagnostic procedure. 
markets may be larger or smaller than those identified by a five- or fifteen-mile radius.

Even if physicians were the sole arbiter of which hospital a patient uses, this merely removes the discussion one step. The issue is then one of competition among physicians. Included in the physician's bag of skills and accoutrements are the hospitals at which he or she has privileges. Thus, even if the economics of medical practice dictate that a given physician would not travel more than, for example, fifteen miles between hospitals, patients may travel much farther than that in search of a preferred bundle of physicianhospital services. If so, the economically relevant hospital market, at a minimum, will be circumscribed by that area in which virtually all patients receive their inpatient care and from which virtually all of the hospital's patients reside.

The economically appropriate market is an empirical question, operationally determined by the flow of patients. With the exception of the Wilder-Jacobs study of two markets and the Garnick comparison of California patient origin data, ${ }^{82}$ this analysis has not been undertaken.

\section{III}

\section{Data ANd Methodology}

To examine the extent of concentration in the hospital market, we defined the product as inpatient short-term acute hospital care. We employed the Elzinga-Hogarty method for determining the market area and the HHI as a measure of concentration.

\section{A. Rural Hospital Analysis}

Data for the analysis of rural hospital markets were drawn from 1984 patient origin data collected and maintained by the Nebraska Department of Health. ${ }^{83}$ Reports developed by the Department provided the number of discharges by each hospital in the state by the patient's county of residence. Non-Nebraskans were identified by state of residence.

Nebraska was chosen for three reasons. First, it is a very rural state with no major physical impediments to patient flow, such as mountains. In 1984, 54 percent of Nebraska's population was located outside of SMSA's. ${ }^{84}$ It had a population density of twenty-one persons per square mile. In contrast, Alabama had a population density of seventy-nine, Minnesota fifty-three, and Wyoming five. ${ }^{85}$ Second, to our knowledge, Nebraska is one of the few rural states that routinely collects patient discharge data. ${ }^{86}$ Finally, Western states

82. See Wilder \& Jacobs, supra note 29; Garnick, supra note 73.

83. State of Nebraska, Dept. of Health, Patient Flow Data, Patient Origin By County, Jan.-Dec. 1984 (unpublished data).

84. U.S. Dep't of Commerce, State and Metropolitan Area Data Book 1986 at xxvi.

85. Id.

86. Complete national compendiums apparently do not exist. The National Association of Health Data Organizations, Statewide Discharge Data System List (Wash., D.C. Jan. 6, 1988) 
tend to have large counties-at least relative to the Northeast. ${ }^{87}$ As a consequence, use of an East or West Coast state may tend to over- or understate, respectively, the number of sole hospital counties. Nebraska, by contrast, contains ninety-three counties: twenty-two counties have no hospital, fifty-three have a single hospital, fourteen have two hospitals, two have three hospitals, one has six hospitals, and one has eleven hospitals. ${ }^{88}$ In 1984, Nebraska had only two SMSA's, Omaha and Lincoln. ${ }^{89}$

1. Sole Hospital Analysis. We began by examining the contention that the county is the exclusive service area of the single hospital located in it. This was done by calculating the percentage of county residents hospitalized outside the county ("exports") and the percentage of residents of other counties hospitalized in the county ("imports").

Our rural analysis was limited to Nebraska counties with only one hospital. We arrayed these counties in alphabetical order and chose every other one for analysis, beginning with the first, Adams County. ${ }^{90}$ We identified those counties necessary to obtain 90 percent of the discharges from the hospital under study. ${ }^{1}$ This satisfied the LOFI rule that there be little export of care to outside the market area.

Beginning with this set of counties, we then determined the percentage of patients residing in these counties that obtained their inpatient hospital care within these counties. We expanded the market by adding counties until 90 percent of the discharges in the market area received their care from hospitals within the market area, thereby satisfying the LIFO rule. In general, this resulted in a group of contiguous counties and one or more urban areas, usually Omaha.

We then summed the squared market shares of each hospital in the market to compute the HHI. Market shares were based upon discharges. If more than one hospital was owned ${ }^{92}$ or contract-managed ${ }^{93}$ by a common firm in the market, we considered these hospitals to be a single firm.

2. Problems of Market Definition. We found urban hospitals in many of the rural markets. This suggests the possibility that we may have defined the

does provide a listing, but it is incomplete in that it excludes Nebraska. California data have been used in related applications. See Garnick, supra note 73, at 74.

87. U.S. Dep't of Commerce, County and City Data Book 498 (1983).

88. State of Nebraska, Dep't of Health, supra note 83 (calculated from county-specific data).

89. See U.S. Dep't of Commerce, supra note 84, at 110, 182. Dakota County is also part of the Sioux City, Iowa, SMSA.

90. To perform the analysis on every rural Nebraska county would have revealed little more and would have been too time-consuming. Also, many of these other counties are in hospital market areas with the counties we explicitly selected for analysis.

91. In satisfying this rule, we included discharges of out-of-state residents. In-state residents receiving inpatient care out of state were lost to the study. As a consequence of ignoring out-of-state hospitals, we overstated hospital concentration.

92. Hospital ownership was determined from the AM. Hosp. Ass'N, Directory of Multihospital Systems, Multistate Alliances, and Networks 1985.

93. Contract management by a system was determined from Am. Hosp. Ass'n, Annual Survey of Hospitals 1984 (unpublished data). 
hospital product too broadly. Rural residents receiving care in urban centers may be doing so because treatment for complex cases was not available locally. If so, we would tend to understate the true level of concentration in the rural markets. Nebraska Department of Health patient origin data do not reveal the reason for patient admission to the hospital. As described below, patient-level hospital discharges were available for this study from Medicare. We used these to determine if rural Nebraska residents who were hospitalized in urban hospitals required more complex care.

In addition, we employed three methods for dealing with the problem of differences in product with Nebraska Department of Health data. First, we recalculated the HHI based upon the LOFI and LIFO rules applied to exports and imports not exceeding 25 percent of discharges ( 75 percent rule). In so doing, the rural counties were less likely to include an urban area. If the hospital care given to patients exported to cities really is different, then the resulting market areas based on the 75 percent rule may indeed be more appropriate. Second, we excluded the urban county and calculated the HHI for the remaining rural market area. Third, for three counties, we excluded all urban area discharges from the number of county residents being discharged. We then recalculated the HHI based upon the 90 percent Elzinga-Hogarty rule. The difference between the second and the third approaches is that, in the second, the urban county was dropped without adding rural counties. In the third, rural counties were added until the threshold figure was reached.

\section{B. Urban Hospital Analysis}

The urban analysis focused on the SMSA as the potentially appropriate definition of the hospital market area. We used a modified Elzinga-Hogarty definition of the geographic market and the October 1984 definition of SMSA's. ${ }^{94}$ We again used patient origin data to define geographic market areas. However, because national data on all hospitalized patients do not exist, we used data on discharges of Medicare beneficiaries from hospitals provided by the Health Care Financing Administration. These data, referred to as the Medpar file, consisted of a 20 percent random sample of all Medicare discharges in the United States in 1982.95 We included only patients aged sixty-five and over ${ }^{96}$ who were discharged from nonfederal short-term general hospitals. The resulting data set contained information on more than two million Medicare discharges. Among the variables available on the file were state and county codes for patient residence, the hospital's Medicare provider number, and the diagnosis related group ("DRG") assigned at the time the patient was discharged from the hospital.

94. See U.S. Dep'T OF Commerce supra note 84, at v-ix.

95. The Medpar file is a public use file available from the Health Care Financing Administration for research purposes.

96. We excluded Medicare beneficiaries under age 65 who were disabled. 
Analyses were performed on three groups of SMSA's: (1) four selected SMSA's, one of which was Omaha, Nebraska, to provide a link with the rural analysis; (2) all SMSA's in the United States; and (3) all SMSA's in Pennsylvania. In each analysis, we merged data on the number of beds in each hospital, a variable identifying the SMSA in which the hospital was located, and a variable identifying the multihospital system that owned or managed the facility. These data were obtained from the American Hospital Association's 1985 Annual Survey of Hospitals. ${ }^{97}$

Once the market areas were defined, the HHI was calculated based upon the number of beds in each hospital firm in the market area. Hospitals owned or managed by the same firm were considered as a single firm.

1. Four Selected SMSA's. We included four major SMSA's in this analysis: Birmingham, Alabama; Omaha, Nebraska; Philadelphia, Pennsylvania; and Phoenix, Arizona. These SMSA's were chosen to represent different regions of the country and different levels of population concentration. ${ }^{98}$ Sites were selected to avoid geographic complexities such as large adjacent bodies of water.

We selected from the Medpar file all discharges of Medicare beneficiaries aged sixty-five and over residing in Alabama, Arizona, Nebraska, and Pennsylvania. We also selected discharges of Medicare beneficiaries aged sixty-five and over from hospitals located in these states, as well as all beneficiaries and hospital discharges from bordering states.

We calculated the percentage of Medicare discharges residing in the SMSA who received care within the SMSA. This is analogous to the Elzinga-Hogarty LIFO measure. We also calculated the percentage of discharges from hospitals in the SMSA who also resided in the SMSA; this is analogous to LOFI. We then compared these values to the Elzinga-Hogarty 90 percent rule. If the market did not satisfy the definition, we added discharges in the counties contiguous to the SMSA and recalculated the LOFI and LIFO percentages. If the original SMSA satisfied the 90 percent rule, we deleted counties within the SMSA and recalculated the LOFI and LIFO terms. We calculated the HHI in each market area we defined.

The market areas may be too large if regionalized tertiary care patients are included with general hospital services. To examine this, we assigned a Medicare DRG weight to each discharge as a measure of the complexity of the hospital case. ${ }^{99}$ Under the Medicare Prospective Payment System, each DRG has been assigned a weight which reflects the mean hospital cost of treating a

97. For a description of the survey, see Am. Hosp. Ass'N, 1986 Hospital Statistics 211.

98. U.S. Dep'r OF COMMERCE, supra note 84, at 2, 182, 262. The 1984 populations per square mile in Birmingham, Omaha, Philadelphia, and Phoenix were 223, 318, 1350, and 188, respectively.

99. This measure of complexity is not perfect. For example, it is unable to account for complex cases that entail the use of a highly trained specialist for diagnosis and case management. The hospitalization may not involve a high weight DRG, but the case is nonetheless complex. Thus, our approach to refining the hospital product definition is only approximate. 
patient in that DRG relative to other DRG's. ${ }^{100}$ We calculated the mean DRG case weight for Medicare patients residing in the SMSA, residing in an adjacent county and receiving care in that county, and residing in an adjacent county but receiving care within the SMSA.

Finally, we reconstructed the markets for all Medicare discharges with a case weight value of 2.5 or below; forty of the 468 DRG's had case weight values above 2.5. Examples of DRG's with weights above 2.5 are: major head and neck procedures (DRG 49); major chest procedures (DRG 75); cardiac value procedures with pump (DRG 105); acute and subacute endocarditis (DRG 126); and splenectomy for those over age 17 (DRG 392). ${ }^{101}$

2. Analysis of All SMSA's. In this analysis, we only used the AHA Annual Survey data to calculate the HHI based upon beds.

3. Analysis of Urban Pennsylvania Areas. In this analysis, we used the same approach as for the four selected SMSA's. We defined the area where both 75 percent of the Medicare beneficiaries residing in the SMSA received their care, and 75 percent of all Medicare hospital discharges in the area were area residents. We then redefined these areas based upon 85 percent and, alternatively, 89 percent of Medicare beneficiaries and hospital discharges being contained in the area. ${ }^{102}$ We then calculated the HHI in each of these areas and compared the results with the original SMSA based HHI.

RESULTS

\section{A. Rural Analysis}

Because of the casual presumption in the industry literature that sole hospital counties are isolated markets, ${ }^{103}$ we first examined the extent to which this was the case in rural Nebraska. In the twenty-seven single hospital counties examined, on average, each hospital received only 54 percent of its discharges from residents of that county (the range was 18 to 98 percent with a standard deviation of 20 percent). In contrast, on average, 72 percent of all discharges of residents living in the county were provided by the sole hospital

100. In 1983, Medicare payment to hospitals was changed from cost-based reimbursement to a prospective payment system. See Vladeck, Medicare Hospital Payment by Diagnosis-Related Groups, 100 ANNALS of InTERnAL MEdicine 576 (1984). The system developed payments for each of 468 DRG's. The DRG's were constructed by using the patient's principal diagnosis, age, sex, and presence of surgery or comorbidity to identify groups of hospital discharges that had similar lengths of stay.

Once constructed, payments were set for each DRG based upon average cost data provided by hospitals. This national set of relative prices is annually adjusted for inflation and other factors. The case weights used in this study are the national set of relative prices established by Medicare. See U.S. Prospective Payment Assessment Comm'n, Medicare Prospective Payment and the American Health Care System, Report to Congress 51 (Feb. 1987), 48 Fed. Reg. at 39,876 (1983).

101. See 48 Fed. Reg. at 39,876-86 (1983)

102. In several SMSA's it was impossible to reach the $90 \%$ rule; $89 \%$, however, was attainable. In a literal sense, this understates the size of the market.

103. See supra note 7 . 
located in that county. (The range was 47 to 93 percent with a standard deviation of 13 percent.)

Figure 1 identifies the number of sole hospital counties that satisfy alternative critical import and export values under the Elzinga-Hogarty approach. Under the common criterion that imports or exports constitute no more than 10 percent of "shipments" (90 percent rule), we determined that no sole hospital county was a market unto itself. Under a 75 percent rule only two counties constituted meaningful markets. Even under the assumption that neither exports nor imports may exceed 40 percent of discharges, only nine of the twenty-seven Nebraska counties analyzed were in self-contained markets. Thus, the relevant geographic markets in the rural parts of Nebraska almost always appear to be larger than one county.

We calculated the market area necessary to satisfy the 90 percent rule. The average market consisted of six counties with a range of two to sixteen counties. The market contained sixteen hospitals on average (range two to twenty-nine).

The mean $\mathrm{HHI}$ in these markets was 2,089 , well below the 10,000 value implied by the sole hospital county. More importantly, only nine of the twenty-seven rural hospital markets had an HHI above the 1,800 level identified in the DOJ Guidelines as highly concentrated. ${ }^{104}$

1. Potential Problems. The foregoing analysis rested upon the assumption that, even if a neighboring hospital did not provide a particular inpatient service, it nonetheless could quickly add it if the price were to rise. However, given the presence of very complex illnesses treated with expensive, technologically sophisticated equipment, such an assumption may be untenable. An analysis of maps of the market areas constructed (not shown) indicated that, in many instances, the market consisted of a group of contiguous counties and an urban center, usually Omaha or Lincoln. This suggests that severe or complex cases may be treated in the urban area and that these clinical services are not part of the product of the rural hospitals.

As discussed above, the DRG case weight, a measure of case complexity, was available for Medicare discharges. ${ }^{105}$ These data permitted a test of differences in case complexity between rural patients treated in their home counties and those treated in Omaha. The 1,366 rural Medicare patients treated in their home county had a mean case weight of 0.96 ; those 486 patients from the same rural counties discharged from Omaha hospitals had an average case weight of 1.11 . The difference was significant at the 1 percent level. This suggests that the rural patients going to the urban centers required more complex hospital care.

The Medicare case weights, however, can take on values substantially above 2.5. Thus, the 0.15 difference suggests that many of the patients treated in the urban areas had maladies that could have been treated in the

104. See 1984 Merger Guidelines, supra note 9.

105. See supra notes 99-100 and accompanying text. 

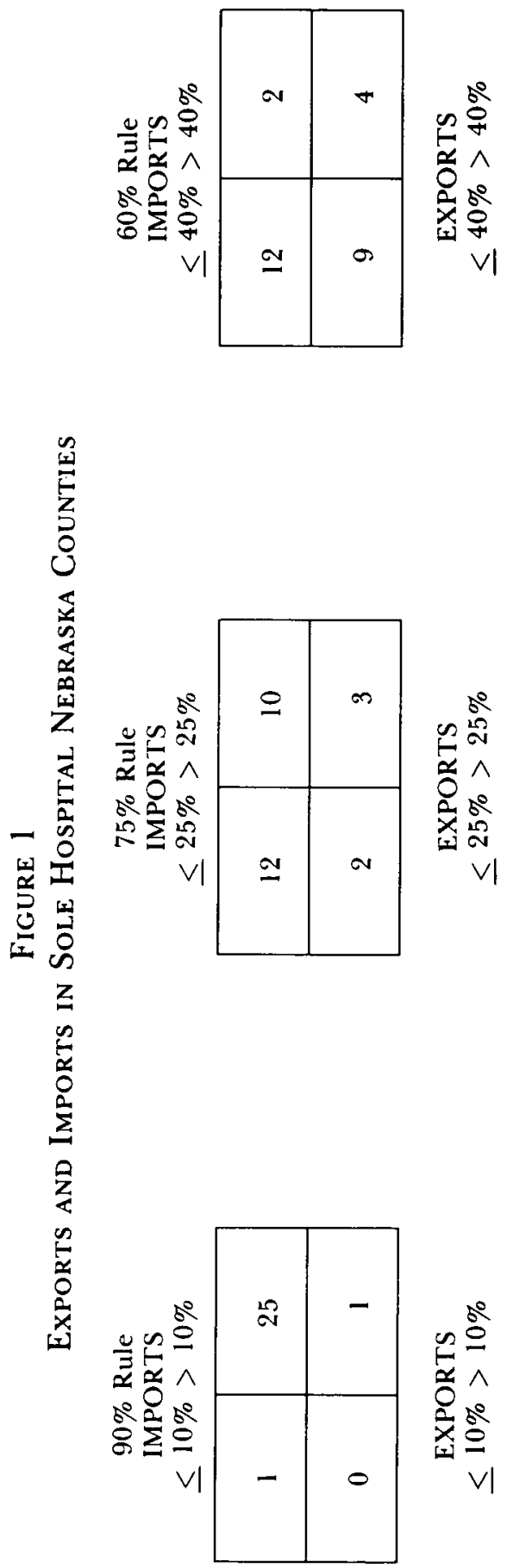
rural hospitals. Further, these data are only suggestive of different products being provided. The relevant issue is how quickly other hospitals could provide the service if a small but significant and non-transitory increase in the price at a competing hospital were to appear.

Nonetheless, we performed three types of sensitivity analysis with Nebraska Department of Health data under the presumption that the cases exported to cities are in fact different. First, suppose the market is defined using a rule requiring only 75 percent of patients to be treated in the market area and only 75 percent of the hospital's discharges to reside in that same area. The result is that the average market area includes 2.5 counties (range of one to six) and 6.2 hospitals (range of one to fourteen). The average HHI rises to 5,047. Eighteen of the twenty-seven market areas have HHI values above 1,800 . However, this approach does not solve the problem of urban area provision of service because many of the markets still include a geographically removed urban center. In many rural markets, the urban center hospitals provide a relatively large number of discharges. Therefore, reducing the rule from 90 percent to 75 percent does not exclude the urban center hospitals.

A second computationally easy approach is to ignore the distant urban hospitals when calculating the concentration measure for the market areas already defined by the 90 percent rule. This must necessarily raise the HHI value in any market with an urban county since the market area is reduced in size. Indeed, only two markets continued to have HHI values below 1,800 . Limiting rural markets to rural counties resulted in wildly different percentages of the discharges treated in the abridged market area. That is, only two markets continued to satisfy the 90 percent rule, and, in one market, only 29 percent of patients continued to receive care in the abridged market. The mean percentage of patients residing in and being discharged from the abridged market was seventy-four, with a standard deviation of seventeen.

A third approach is to exclude the distant urban center and recalculate the market area based upon the 90 percent rule for only the rural counties. We performed this recalculation for the first three rural counties having a distant urban center in its market area. The result raised or left unchanged the number of counties and hospitals in the market area. For example, Butler County's market grew from five counties and sixteen hospitals to twenty counties and twenty-six hospitals. In many of the added counties, there were few exports and imports between the county and Butler County. Yet, we needed the county to reach the 90 percent threshold. The newly defined market area in each instance had a higher HHI value than originally, but still below 1,800 .

Our experiments show that care received by rural residents in urban hospitals is quantitatively important. Estimates of rural market areas, based on shipments data, are quite sensitive to whether one includes or excludes the rural to urban hospital migrants. The critical question to be addressed below 
is whether and to what extent these migrants are different from rural residents treated in rural hospitals.

\section{B. Urban Analysis}

We first examined hospital imports and exports at the SMSA level in each of the four cities shown in Table 1. In Birmingham, Omaha, and Phoenix, residents seldom left the SMSA for inpatient treatment, but a high percentage of the cases treated came from elsewhere. In Phoenix, for example, nearly 19 percent of discharges resided outside the SMSA.

\section{TABLE 1 \\ Market Areas of Four Major SMSA's*}

\begin{tabular}{lcc} 
SMSA & \% Exports & \% Imports \\
\hline Phoenix & & \\
SMSA & 8.6 & 18.7 \\
SMSA and adjacent counties & 6.6 & 13.4 \\
Birmingham & & \\
$\quad$ SMSA & 3.7 & 19.6 \\
SMSA and adjacent counties & 4.9 & 9.5 \\
Omaha & & 30.0 \\
SMSA & 5.0 & 17.5 \\
SMSA and adjacent counties & 7.0 & 11.8 \\
SMSA and adjacent counties and outlying & & \\
$\quad$ counties & 7.5 & 7.4 \\
Philadelphia & & 11.8 \\
SMSA & 5.0 & 10.4 \\
Sub-SMSA' & 6.3 & \\
Sub-SMSA & &
\end{tabular}

* Market areas have been defined with data on Medicare beneficiary discharges from the 1982 Modified Medpar File.

I Philadelphia, Montgomery, Delaware counties.

2 Philadelphia, Montgomery, Delaware, Chester counties.

We expanded the geographic area to include those counties adjacent to the SMSA. This satisfied the 90 percent rule for Birmingham, but not for Omaha or Phoenix. In Omaha, even the expansion to include outlying counties in the remainder of Nebraska and lowa that sent a sizeable proportion of residents to Omaha, was insufficient to form a market using the Elzinga-Hogarty 90 percent rule. In Phoenix, the presence of seasonal residents, or "snow birds," appears to have caused the high percentage of imports. The Medpar file listed the residency of such people as a distant state but the hospital of discharge was in Phoenix. It is more likely that these people became sick while in Phoenix than it is that they came to Phoenix from several states away expressly to receive hospital care.

In contrast, the SMSA was sufficient to define the Philadelphia market, and may even have been too large. Restricting the market to only Pennsylvania 
counties in the Philadelphia SMSA, however, did not quite satisfy the 90 percent rule.

Based on this small sample, it appears that the SMSA is often too small a measure of the relevant urban hospital market. Furthermore, the extent to which the market area is understated appears to depend upon the proximity of other SMSA's. An SMSA located in an otherwise rural area appears to have a geographic market much larger than the SMSA. In SMSA's located near other SMSA's, the geographic market appears to be approximated by the SMSA boundaries, with relatively few imports or exports across those boundaries.

Like rural markets, markets defined in this way may be too large because tertiary and nontertiary services have been included in the product. We examined the mean DRG case weight for the three SMSA's which had markets larger than the SMSA itself (Table 2). In each instance, patients residing outside the SMSA but treated within the SMSA had a higher mean case weight (were more complex cases) than those being treated in their home county.

TABLE 2

Mean DRG Weight of Medicare Beneficiaries by Distance from SMSA

\begin{tabular}{|c|c|c|c|}
\hline & $\begin{array}{c}\text { Number of } \\
\text { Observations }\end{array}$ & $\begin{array}{c}\text { Mean DRG } \\
\text { Weight }\end{array}$ & $\begin{array}{c}\text { Standard } \\
\text { Deviations }\end{array}$ \\
\hline \multicolumn{4}{|l|}{ Phoenix } \\
\hline Within SMSA & 11,413 & 1.10 & 0.59 \\
\hline \multicolumn{4}{|l|}{ Adjacent to SMSA } \\
\hline Treated in own county & 6,048 & 1.06 & 0.56 \\
\hline Treated in Phoenix & 813 & $1.15^{*}$ & 0.67 \\
\hline \multicolumn{4}{|l|}{ Omaha } \\
\hline Within SMSA & 5,360 & 1.02 & 0.50 \\
\hline \multicolumn{4}{|l|}{ Adjacent to SMSA } \\
\hline Treated in own county & 1,290 & 0.97 & 0.40 \\
\hline Treated in Omaha & 860 & $1.07 *$ & 0.58 \\
\hline \multicolumn{4}{|l|}{ Outlying } \\
\hline Treated in own county & 1,366 & 0.95 & 0.40 \\
\hline Treated in Omaha & 486 & $1.11^{*}$ & 0.61 \\
\hline \multicolumn{4}{|l|}{ Birmingham } \\
\hline Within SMSA & 9,857 & 1.03 & 0.54 \\
\hline \multicolumn{4}{|l|}{ Adjacent to SMSA } \\
\hline Treated in own county & 5,986 & 0.96 & 0.43 \\
\hline Treated in Birmingham & 1,310 & $1.15^{*}$ & 0.75 \\
\hline
\end{tabular}

* Significantly different from the estimate immediately above at the one \% level, two-tail ttest.

Source: 1982 Modified Medpar File

Would the exclusion of very complex cases result in a smaller urban market area? To address this issue, we computed the percentage of imports and exports in each market after excluding all patients with complex cases (Table 3). "Complex" was defined as having a DRG weight of 2.5 or above. 
The results were virtually unchanged. Thus, the SMSA hospitals appear to have competed with hospitals outside the SMSA for noncomplex cases.

TABLE 3

Market Areas for Four Major SMSA's*

\begin{tabular}{|c|c|c|c|c|}
\hline & \multicolumn{2}{|c|}{ \% Exports } & \multicolumn{2}{|c|}{ \% Imports } \\
\hline & & DRG's with & & DRG's with \\
\hline & All DRG's & Wt. $<2.50$ & All DRG's & Wt. $<2.50$ \\
\hline \multicolumn{5}{|l|}{ Phoenix } \\
\hline SMSA & 8.6 & 6.3 & 18.7 & 15.2 \\
\hline SMSA and adjacent counties & 6.6 & 4.9 & 13.4 & 10.6 \\
\hline \multicolumn{5}{|l|}{ Birmingham } \\
\hline SMSA & 3.7 & 3.6 & 19.6 & 16.7 \\
\hline SMSA and adjacent counties & 4.9 & 4.9 & 9.5 & 7.3 \\
\hline \multicolumn{5}{|l|}{ Omaha } \\
\hline SMSA & 5.0 & 5.0 & 30.0 & 29.3 \\
\hline SMSA and adjacent counties & 7.0 & 7.3 & 17.5 & 17.2 \\
\hline SMSA and adjacent counties & & & & \\
\hline and outlying counties & 7.5 & 7.5 & 11.8 & 11.6 \\
\hline \multicolumn{5}{|l|}{ Philadelphia } \\
\hline SMSA & 4.4 & 4.4 & 7.0 & 6.4 \\
\hline Sub-SMSA1 $^{1}$ & 6.0 & 5.7 & 11.4 & 11.4 \\
\hline Sub-SMSA2 $2^{2}$ & 5.8 & 5.7 & 10.3 & 10.1 \\
\hline
\end{tabular}

* Market areas have been defined with data on Medicare beneficiary discharges from the 1982 Modified Medpar File.

1 Philadelphia, Montgomery, Delaware counties.

- Philadelphia, Montgomery, Delaware, Chester counties.

In general, using the SMSA as the appropriate geographic market in which to calculate hospital concentration in urban areas results in markets, which, except for the largest urban areas, are highly concentrated (see Table 4 on next page). Of the 336 SMSA's, 247 had HHI values above the 1,800 level identified as highly concentrated by the DOJ Guidelines. ${ }^{106}$

The four-market analysis suggests that many of these urban markets have appropriately defined markets that are larger than the SMSA. Using the Medpar data, we examined fourteen of the fifteen SMSA's in Pennsylvania. ${ }^{107}$ Since Pennsylvania is a predominantly urban state ${ }^{108}$ with a large number of SMSA's, the appropriately defined market should more nearly approximate the SMSA than in less urban states. We began with the SMSA and added adjacent counties until 75 percent, 85 percent, and 89 percent rules were satisfied under the Elzinga-Hogarty shipments approach to defining market areas. We used the 89 percent rule because in several markets, we were

106. 1984 Merger Guidelines, supra note 9.

107. One Pennsylvania SMSA, State College, was deleted from analysis due to insufficient cases in the Medpar file.

108. Most Pennsylvania residents $(84.5 \%)$ reside in metropolitan areas. U.S. DEP'T of Commerce, supra note 84 , at xxvi. 
TABLE 4

SMSA's by Number OF HoSPITAL FIRMS

\begin{tabular}{|c|c|c|c|c|c|c|c|c|}
\hline \multicolumn{9}{|c|}{ SMSA's with } \\
\hline & & $\begin{array}{c}1 \\
\text { Hosp }\end{array}$ & $\begin{array}{c}2 \\
\text { Hosp }\end{array}$ & $\begin{array}{c}3 \\
\text { Hosp }\end{array}$ & $\begin{array}{c}4 \\
\text { Hosp }\end{array}$ & $\begin{array}{c}5 \\
\text { Hosp }\end{array}$ & $\begin{array}{c}6-10 \\
\text { Hosp }\end{array}$ & $\begin{array}{l}11+ \\
\text { Hosp }\end{array}$ \\
\hline No. of SMSA's & : & 16 & 62 & 41 & 43 & 29 & 79 & 66 \\
\hline $\begin{array}{l}\text { Mean Population } \\
\quad \text { (in 1000's) }\end{array}$ & $\begin{array}{l}: \\
: \\
:\end{array}$ & 107 & 143 & 160 & 192 & 260 & 426 & 1,750 \\
\hline Mean Herfindahl & : & 10,000 & 5,832 & 4,083 & 3,515 & 2,705 & 2,149 & 874 \\
\hline $\begin{array}{l}\text { Percent of SMSA's } \\
\text { with mean } \\
\text { Herfindahl }>1800\end{array}$ & : & 100.0 & 100.0 & 100.0 & 100.0 & 100.0 & 70.9 & 0.0 \\
\hline
\end{tabular}

unable to reach 90 percent without adding several additional counties. Only in each of the four largest SMSA's was the market unconcentrated when the geographic market was defined as the SMSA (see Table 5 on next page). However, all but three of the Pennsylvania SMSA markets were expanded by application of the 89 percent rule. The HHI values recalculated on this more appropriate definition suggest few problems of concentration. Only four of the fourteen markets examined had HHI values above 1,800 .

V

\section{Discussion}

In this analysis, we used the Elzinga-Hogarty approach to market definition to identify the geographic market for hospital care. The hospital product was defined as acute care hospital inpatient services. Using this method, we found that hospital markets are both much larger and much less concentrated than most previous studies have implied. Although the shipments approach defines an area more closely akin to an economic than an antitrust market, knowledge of the former provides a major first step for learning about the latter. If patients were only willing to travel up to three miles to receive hospital care under current prices, it would not be plausible to suggest that they would travel up to fifty miles from the town if the local hospitals raised their prices by a small but significant amount. Furthermore, while mergers or acquisitions in some markets will clearly trigger a review based upon the 1984 DOJ Guidelines, these instances will be the exception, not the rule. ${ }^{109}$

109. 1984 Merger Guidelines, supra note 9. 


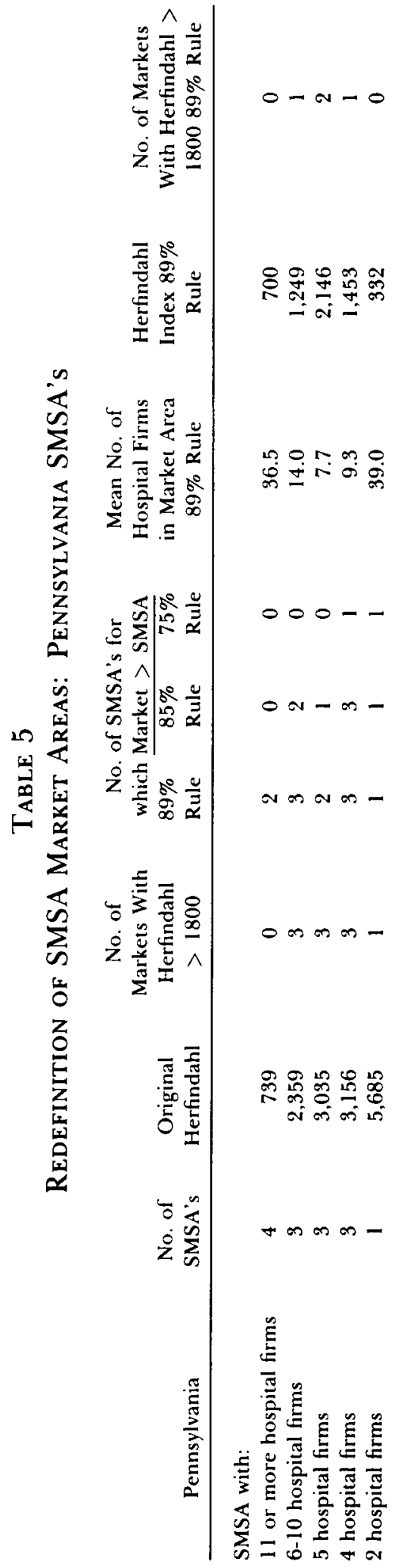




\section{A. Limitations}

Our estimates of the extent of hospital market concentration are likely to be overstated for two reasons. First, we have focused only on hospitals. To the extent that physicians' offices, surgicenters, and other sources of ambulatory care provide substitute sources of care, the measured level of concentration is too high. Second, in defining geographic markets for rural areas, we only included out-of-state patients entering the state for care; we had no way to measure out-of-state bound patients. We have thus ignored hospital competitors residing outside state boundaries. This too has the effect of artificially raising the measured level of concentration.

There are four general issues of concern with our approach. The first has to do with substitutability of supply among hospitals. Our approach assumes that even if a hospital does not currently offer hernia repairs or total hip replacements, for example, it could easily and swiftly do so. The issue becomes more complex when one considers service changes which require certificate-of-need ("CON") review."10 Although states are no longer required by federal statute to have a CON program, and several states do not, ${ }^{111}$ CON requirements still exist in the majority of states. While there is some question that CON ever really impeded diffusion of medical technology in the hospital sector, ${ }^{112}$ the CON process is time-consuming and provides a forum for competitors to oppose new entry. It therefore delays a supply response and raises transaction costs associated with new entry.

The second potential concern is that a 90 percent rule may be too high to capture the relevant market meaningfully. Elzinga and Hogarty expressed a preference for the 90 percent rule because it results in overlapping markets and thus is more consistent with "the real world." 13 In the application to hospitals, the key issue is patient willingness to travel. If there is little willingness, then the concentration rate in the 90 percent rule will approach that of the 75 percent rule. Alternatively, if people do commonly travel some distance, the higher rule is more meaningful. Our data suggest that significant travel distances do commonly occur in hospital markets. This logic, of course, depends upon meaningful product definition. Substantial travel may only reflect access to high technology or unique services. Our findings, however, indicate that even after excluding complex cases, patients still traveled long distances, particularly in rural areas.

Third, the market areas reflect hospital prices in the year the patient flows were measured. Yet exports and imports and, hence, the computed market areas may respond to price changes. If two hospitals in a town were to merge and successfully raise prices, the market area might contract, as only local

110. Lynk, supra note 29 , at 72 (CON review may blunt competition among existing providers and inhibit new entry). For a discussion of CON review, see Joskow, supra note 7, at 433-34.

111. See P. Feldstein, Health Care Economics 274 (1988).

112. See Russell, supra note 6, at 162; Sloan, Valvona, Perrin \& Adamache, Diffusion of Surgical Technology: An Exploratory Study, 5 J. HeAlth Econ. 31, 45, 47 (1986).

113. Elzinga \& Hogarty, The Case of Coal, supra note 17, at 2. 
citizens would continue to receive care. The market area might also expand as the geographic range necessary to satisfy the LIFO definition that 90 percent of the persons in the area receive care there. It is impossible to state, a priori, whether the computed market would expand or shrink.

Fourth, the data only indicate that, under prevailing circumstances, patients were willing to travel in the ways we have described. However, description is only a first step. It is often important to know why patient flow patterns are observed. In some cases, patient travel may itself be a response to an action that merits scrutiny from an antitrust perspective. Suppose, for example, that a certain type of physician is denied staff privileges at a hospital.14 To receive care from such physicians in a hospital setting, patients may then have to travel a considerable distance. Although large market areas may be generally consistent with a greater degree of competition, in some cases, market areas may be enlarged because of an anticompetitive restraint.

\section{B. Implications for Antitrust Policy in the Hospital Field}

1. Rural Hospital Markets. Rural hospital markets, at least in such states as Nebraska, are relatively large. In Nebraska, markets encompassed six counties, on average, and contained sixteen hospitals. In most instances, the markets were not highly concentrated; only one-third had $\mathrm{HHI}$ values exceeding the 1,800 mark established by the DOJ Guidelines.

This finding is well below the level required to support common assertions that all rural hospitals are virtual monopolists. ${ }^{115}$ The markets, while geographically large, reflect a willingness of patients to travel some distance to a rival hospital. As a consequence, the acquisition of a single rural hospital does not necessarily lead to monopoly pricing, even when the hospital is the only facility in the county. A merger of hospitals in a rural market need not result in lessening of competition, although the facts will differ in each instance. Indeed, given the presence of a distant urban center in the rural market, such a merger may actually increase the competition with urban hospitals. A large size may permit a more varied service offering, giving patients less reason to travel to receive care in a city.

As seen above, many rural hospital markets include an urban center in the relevant market. One would suppose that this is a manifestation of a misspecification of the hospital product. Complex or serious cases may be transferred or sent directly to urban regional referral centers or tertiary care hospitals. Our data lend only partial support to this view. Even when complex cases are excluded, the urban hospitals attract a substantial share of their volume from outlying areas. Thus, it appears that the urban centers do compete for patients with their rural neighbors and therefore should be included in the appropriate market.

114. We thank James Blumstein for the example.

115. See Farley, supra note 56, at 7; Joskow, supra note 7, at 436; Luft \& Maerki, supra note 7, at 100 . 
In one experiment we conducted, we completely excluded the urban centers from the analysis of rural markets, but still applied the same LIFOLOFI rule as we did when the urban areas were included. The rural markets then encompassed more counties on average. The number of hospitals in the new market tended to be smaller, but in the few counties we examined, the HHI value did not increase enough to reach the DOJ Guidelines on concentrated markets.

This may be a result of planning by rural hospitals that have specialized in noncompeting services. One hospital may choose obstetrics and another orthopedics, for example. There are two reasons to doubt this, however. First, the literature on urban hospital competition suggests strong non-price competition. ${ }^{116}$ If the studies were performed on properly drawn rural markets, the results might have been similar; indeed, the underlying payment incentives (that is, nearly complete retrospective reimbursement for hospital care) are the same. Second, the product of the hospital is general inpatient hospital services. Newhouse, Williams, Bennett, and Schwartz have shown that there has been an increased flow of physicians into rural areas in recent years. They found increased probabilities of most general specialties (for example, internal medicine, general surgery, obstetrics, and pediatrics) in towns with 2,500 people during the 1970 's. ${ }^{117}$ The increased supply of physicians suggests that if market-sharing deals were made by hospitals early on (if indeed they were), they have come under extreme pressure in the last decade. Young specialist entrants to rural markets would not be pleased if their access to the local hospital were foreclosed because the hospital decided to concentrate on procedures outside the scope of their specialties.

It could also be argued that hospitals and their existing medical staffs have maintained a policy of closed staffing which forces physicians to send their patients to distant hospitals for care in a particular specialty area. It is probably not in the hospital's best interest to follow this policy. While the medical staff can benefit from a policy of closed staffing, ${ }^{118}$ if the medical staff is not the residual claimant, it is not at all clear that it is in the hospital's business interest to close the staff. The growth of competition among hospitals is increasingly forcing hospitals to act in their own interests rather than as "workshops" for their medical staff."19

The competitive environment for hospitals is rapidly changing. Hospitals have begun to advertise. ${ }^{120}$ The Health Care Financing Administration has

116. See Farley, supra note 56; Frech \& Woolley, supra note 52; M. Noether, supra note 52; Robinson \& Luft, supra note 32; Robinson \& Luft, supra note 71.

117. Newhouse, Williams, Bennett \& Schwartz, Does the Geographical Distribution of Physicians Reflect Market Failure?, 13 BELL J. ECON. 493, 501-02 (1982).

118. See Pauly \& Redisch, The Nol-for-Profit Hospital as a Physicians ' Cooperative, 63 Am. EcoN. REv. $87,90-93$ (1973).

119. Blumstein \& Sloan, Antitrust and Hospital Peer Review, Law \& Contemp. Probs., Spring 1988 , at 7, 17-18. See also Morrisey \& Brooks, The Myth of the Closed Medical Siaff. Hospitals, July 1, 1985, at 75.

120. See Steiber, Marketing Budgets Increase a Modest +\%. HospItals, Nov. 20, 1987, at 52. 
published hospital-specific mortality rates. ${ }^{121}$ More important than the rates themselves is the fact that a payer such as Medicare now is beginning to make quality-of-care comparisons among hospitals. Enrollments in "prudent purchasing plans," such as preferred provider organizations and health maintenance organizations, have risen rapidly in recent years. ${ }^{122}$ These plans typically demand "more care for the buck" and secure discounts because they are able to deliver a high volume of patients. In return for savings, patients give up the freedom of choice of provider. The growth in advertising, explicit quality-of-care comparisons, and increased market share of prudent purchasers all suggest that market areas, even rural ones, will expand in the future.

2. Urban Markets. Our analysis of urban markets began with the assumption, following the analysis of others, that the SMSA is generally the appropriate market area. Based on our analysis of patient origin data, we concluded that the market is at least this large and typically larger. Using more appropriate measures for the boundaries of urban markets, we found that most urban hospital markets are not likely to be highly concentrated, although even with the larger market definition, some of the smaller urban markets are. This result suggests that, while antitrust review is important, in most cases, mergers are unlikely to harm competition.

We found that SMSA's are more likely to be the appropriate market when they are located in heavily urbanized regions with several nearby SMSA's. This is not surprising since the definition of an SMSA is based, in part, on flows of commerce. ${ }^{123}$ If correctly drawn, a cluster of SMSA's should reflect several distinct markets. There should be relatively little retail commerce between the SMSA's. Our analysis of the Philadelphia hospital market was consistent with these hypotheses. However, even in urban regions with several SMSA's, we found that hospital markets were generally larger than the SMSA itself.

By contrast, hospital market areas centered in SMSA's surrounded by more rural regions appear to be larger than the SMSA's, as people from outlying areas are drawn to the SMSA for goods and services. This theory was borne out by our studies of Birmingham, Phoenix, and particularly Omaha. Thus, when the urban area is not in close proximity to other SMSA's, it is important for antitrust analysis to pay more attention to the number of potential competitors in outlying areas.

The urban market presents the flip-side of the rural market-complex case argument. There will generally be one or more hospitals in an urban area treating the most complex cases. We found that excluding the most complex

121. See HCFA Releases Hospital Mortality Data; 146 Providers Exceed Normal Ranges, 41 MED. \& HeAlth 1 (1987).

122. Kenkel, Managed-Care Growth Continued in 1987 Despite Companies' Poor Operating Results, Modern Healthcare, June 3, 1988, at 21; Rice, delissovoy, Gabel \& Ermann, The State of PPOs: Results from a National Survey, Health Afrs., Winter 1985, at 25, 30.

123. U.S. DEP'T OF COMMERCE, supra note 84, at 674. 
patients (cases with DRG weights above 2.5) from the analysis did not shrink the size of the urban hospital market appreciably. Hence, the urban market area definition does not appear to depend upon whether specialized services are excluded or included. There exist measures of case complexity other than the DRG-based measure, but, even an analysis using a variety of such measures shows clearly that so called "tertiary hospitals" deliver a considerable amount of not-so-complex care. ${ }^{124}$

If the "tertiary care" of major teaching institutions were not part of the local market for general hospital services, a local merger with such a hospital would raise issues of vertical, but not horizontal, integration, and the economic case of monopoly harm would be harder to establish. ${ }^{125}$ Given the case mix of major teaching hospitals up to now, ${ }^{126}$ it would be difficult to argue that a combination between a major teaching and nonteaching hospital would typically be vertical. A few high technology hospitals appear to be competing in a more national market. There are consumer information guides identifying the premier institutions nationwide by specialty area. ${ }^{127}$

It has also been suggested that physicians will only travel a few miles between hospitals, and that this fact limits the extent of competition. ${ }^{128}$ Even if fifteen miles were the most physicians were willing to travel, many patients receive medical or surgical care in the hospital from physicians other than their usual physician. If the marginal patient is willing to incur greater travel costs, then the market will be larger. Indeed, our patient flow data are consistent with this view. ${ }^{129}$

124. See Sloan, Perrin \& Valvona, The Teaching Hospital's Growing Surgical Caseload, 254 J. A.M.A. 376 (1985).

125. See Bork, Vertical Integration and the Sherman Act: The Legal History of An Economic Misconception, 22 U. Chi. L. Rev. 157 (1954); McGee \& Bassett, Vertical Integration Revisited, 19 J. L. \& Econ. 17, 31 $32,37.38$ (1976).

126. See Sloan, Morrisey \& Valvona, Case Shifting and the Medicare Prospective Payment System, 78 AM. J. Pub. Health 553, 554 (1988).

127. See, e.g., H. Dietrich \& V. Biddee, The Best in Medicine (1986).

128. See Luft \& Maerki, supra note 7, at 91 .

129. In addition to the antitrust implications, there are four other issues that warrant a brief mention as a result of this analysis.

First, if rural markets are as large as this analysis suggests, there is little reason for the Medicare sole community provider exemption. So-called "sole provider" hospitals will continue to receive three-fourths of their Medicare Part A payment on a cost-based retrospective basis and only onefourth on a prospective basis. Fed. Reg., supra note 5. Since rural hospitals have several competitors, there is little justification for special payment rules that help protect the isolated hospital from the adverse consequences of lower payment.

Second, there is growing concern that hospitals, and rural hospitals in particular, are likely to close as a result of Medicare prospective payment and other changes in the industry. See Mullner \& McNeil, Rural and Urban Hospital Closures: A Comparison, Health AfFs., Fall 1986, at 131. Our study of rural markets suggests that the concern over access to care is not a critical issue in most cases. Rural citizens in nonemergency situations appear to have access to multiple hospitals and are not meaningfully limited to a single critical facility.

Third, our results suggest that urban and rural hospitals often are in a common geographic market. Thus, payment distinctions based upon urban or rural location (such as Medicare's) distort the functioning of the hospital market.

Finally, our analysis of hospital markets may have implications for other health services. Particularly, Medicare has developed the Average Adjusted Per Capita Cost ("AAPCC") method for compensating health maintenance organizations and competitive medical plans. Under the system, 
If anything, the growth of competition among hospitals, as reflected in trends in advertising, publication of hospital-specific mortality rates, and the market share of prudent purchasers of care, should increase the size of most hospital markets. This does not necessarily mean, however, that there will be a reduced role for antitrust enforcement in the hospital field. Some hospitals may seek to merge rather than face the rigors of competition. They may reason that, if they merge, the health maintenance organization or preferred provider organization would be forced to deal with them, or that they could realize savings in marketing costs. Even if such attempts to forestall competition may prove fruitless in the long run, they may be harmful in the shorter term.

\section{VI}

\section{Conclusion}

In short, the proper definition of hospital market areas has significant effects on the extent to which the hospital industry is concentrated. We have found the markets we studied generally to be unconcentrated. This suggests that antitrust concerns may be an issue in fewer hospital markets than conventional wisdom would have predicted.

providers are paid a per capita payment based upon $95 \%$ of the average per capita Medicare expenditures in the county in which the beneficiary lives. See Fed. Reg. 1,314 (1985). This has resulted in large payment variations across counties. If these firms compete in markets similar to hospitals, then the county is much too small a definition. Larger, more appropriate market areas could be easily constructed from the Medpar data used in this study. 